\title{
Pengaruh Inflasi, Kurs, dan Harga Emas Terhadap Penyaluran Rahn (Studi Pada Bank Syariah Mandiri)
}

\author{
Soeharjoto $^{\left.1^{*}\right)}$, Debbie Aryani Tribudhi ${ }^{2)}$, Dini Hariyanti ${ }^{3)}$, Lucky Nugroho $^{4)}$, Engkur $^{5)}$ \\ ${ }^{1,2,3}$ Fakultas Ekonomi dan Bisnis, Universitas Trisakti \\ ${ }^{4}$ Fakultas Ekonomi dan Bisnis, Universitas Mercu Buana \\ ${ }^{5}$ Sekolah Tinggi Ilmu Ekonomi Indonesia \\ *Email korespondensi: soeharjoto@ trisakti.ac.id
}

\begin{abstract}
Indonesia, with a Muslim majority population, has made Islamic financial institutions develop rapidly. To meet community needs, Bank Syariah Mandiri developed alternative financing, by issuing gold pawn products (Rahn). Aims of this study is to determine factors that influence Rahn distribution. Used regression method with quarterly data in 2011-2018. Dependent variable is Rahn distribution and inflation, exchange rate and gold price as the independent variable. Result shown that inflation and gold price have a positive and significant effect on Rahn's distribution, while the exchange rate has a negative and significant effect on Rahn's distribution. For this reason, financial institutions can develop gold pawns by utilizing financial technology, and Government needs to maintain stable inflation and exchange rates in order to increase economic growth and income distribution.
\end{abstract}

Keywords: Rahn, inflation, exchange rate, gold price

Saran sitasi: Soeharjoto., Tribudhi, D. A., Hariyanti, D., Nugroho, L., \& Engkur. (2021). Pengaruh Inflasi, Kurs, dan Harga Emas Terhadap Penyaluran Rahn (Studi Pada Bank Syariah Mandiri). Jurnal Ilmiah Ekonomi Islam, 7(02), 687-692. doi: http://dx.doi.org/10.29040/jiei.v7i2.2411

DOI: http://dx.doi.org/10.29040/jiei.v7i2.2411

\section{PENDAHULUAN}

Indonesia merupakan negara anggota Group of Twenty dan Association of Southeast Asian Nations, dengan pertumbuhan ekonomi rata-rata sebesar 5,37 persen pada 2011-2018, memiliki prospek ekonomi yang baik (Astuti, 2020). Keberhasilan ini merupakan kontribusi besar dari lembaga keuangan khususnya pembiayaan yang berperan sebagai penggerak roda perekonomian nasional (Tribudhi, \& Soekapdjo, 2019). Lembaga pembiayaan di Indonesia merupakan lembaga keuangan yang menerapkan dual banking system secara konvensional dan syariah (Soekapdjo, Nugroho, Badawi, \& Utami, 2018). Untuk itu, dalam menekan risiko yang dihadapi, pelaksanaan pembiayaannya dilakukan dengan membuat kesepakatan antara pihak peminjam kepada lembaga keuangan, untuk mengembalikan kewajibannya pada saat jatuh tempo dan memberikan imbalan atau bagi hasil (Dja'akum, 2017).

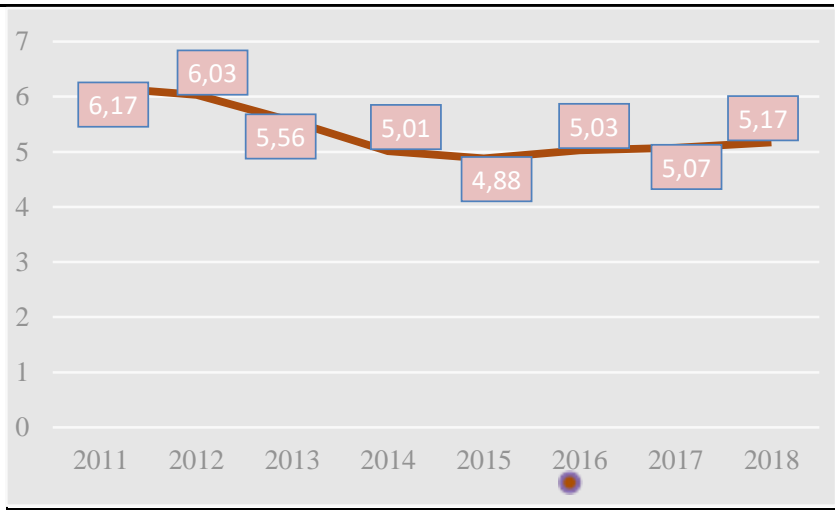

Gambar 1. Pertumbuhan Ekonomi di Indonesia Pada 2011-2018 (Persen)

Sumber: World Bank Data, 2020

Perekonomian di Indonesia pada 2011-2018, memiliki pertumbuhan di atas lima persen, tetapi pertumbuhan pendapatan per kapitanya rata-rata hanya sebesar 4,18 persen dengan tren yang menurun. Kondisi ini, mengindikasikan bahwa pertumbuhan pendapatan masyarakat berada di bawah nasional. 


\section{Jurnal Ilmiah Ekonomi Islam, 7(02), 2021, 688}

Dalam upaya meningkatkan pertumbuhannya, masyarakat memerlukan lembaga pembiayaan dalam menopang investasinya (Fadilah, \& Soeharjoto, 2016). Untuk itu, diperlukan lembaga keuangan pembiayaan alternatif, berupa lembaga gadai yang dapat memberikan rasa aman dan kepastian, sehingga dapat mengurangi risiko kehilangan barang berharga yang dijaminkan (Malarangan, Irfan, Haekal, \& Istiqamah, 2020).

Pada era kini, aktivitas gadai dilakukan lembaga jaminan pegadaian konvensional dan syariah (Setiawan, 2015). Dalam praktik gadai syariah menghindari terjadinya riba (Surepno, 2018). Untuk itu, dalam penerapannya produk gadai emas syariah menggunakan Peraturan Bank Indonesia Nomor. 10/17/PBI/2008 tentang Produk Bank Syariah dan Unit Usaha Syariah, Surat Edaran Bank Indonesia Nomor. 10/31/DPbS/2008 tentang Produk Bank Syariah dan Unit Usaha Syariah, Surat Edaran Bank Indonesia (SE-BI) Nomor 14/7/DPbS tentang Produk Qardh beragunan Emas bagi Bank Syariah dan Unit Usaha Syariah, Fatwa DSN-MUI Nomor.25/DSNMUI/III/2002 tentang Rahn, dan Fatwa DSN-MUI Nomor 26/DSNMUI/2002 tentang rahn emas. Kesemuanya diterapkan agar produk yang dihasilkan terjamin kehalalan dan toyiban, sehingga akan membawa keberkahan di dunia dan akhirat.

Emas merupakan komoditi yang likuid dan nilainya stabil, sehingga dijadikan sebagai jaminan pinjaman (Fauziah, 2019). Hal ini, sejalan dengan banyaknya masyarakat yang menyukainya sebagai perhiasan dan investasi (Fauziah, \& Surya, 2016). Kedua hal ini, akhirnya membuat semakin berkembangnya lembaga pembiayaan yang menerapkan jaminan dalam bentuk emas. Penggunaan emas sebagai alat tukar sudah ada pada zaman Rasulullah. Komoditi ini, telah disebutkan beberapa kali dalam ayat Al-Qut'an, seperti yang terdapat dalam surat Al Imran ayat 91, At Taubah ayat 34 dan Al Imran ayat 14. Gadai atau Rahn merupakan menahan sesuatu benda yang memiliki nilai ekonomis (Turmudi, 2016). Artinya, pihak yang memberikan utang memiliki jaminan untuk mengambil kembali sebagian atau seluruh piutangnya apabila pihak peminjam tidak dapat membayar utang sesuai dengan kesepakatan. Hal ini, dapat mengurangi risiko gagal bayar dari perjanjian pinjam meminjam, sehingga tidak ada pihak yang dirugikan. Bank Syariah Mandiri merupakan salah satu bank syariah yang menawarkan produk gadai emas (Diana, 2017). Produk gadai emas merupakan diversifikasi dari produk yang dibuatnya, untuk menunjang keberhasilan pengembangan bank, dengan menerapkan prinsip syariah, dan sekaligus meningkatkan pendapatan masyarakat, karena pertumbuhan harga emas dan penyaluran Rahn memiliki kecenderungan arah tren yang sama, sehingga dapat memperoleh keberkahan berupa keuntungan pada kedua belah pihak.

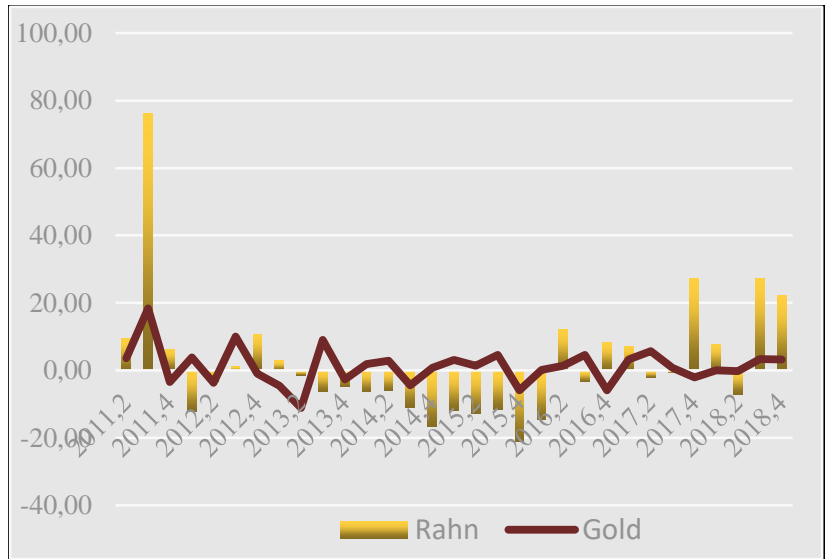

Gambar 2. Pertumbuhan Harga Emas dan Penyaluran Rahn di Indonesia (Persen) Sumber: Antam dan BSM, 2020.

Dalam penyaluran Rahn, untuk mengurangi risiko yang terjadi dengan memperhatikan kondisi internal dan eksternalnya. Hal ini, mengingatkan bahwa walaupun faktor internal masih dapat dikendalikan perusahaan, tetapi faktor eksternalnya tidak. Namun demikian, faktor ekternal memiliki peran besar terhadap perkembangan ekonomi nasional (Soekapdjo, \& Danova, 2020). Untuk itu, dalam penyaluran Rahn perusahaan gadai perlu memperhatikan kestabilan makro ekonomi di Indonesia sebagai faktor ekternalnya yang banyak dipengaruhi perekonomian dunia.

Penyaluran Rahn dan pembiayaan syariah sudah dilakukan beberapa peneliti. Penelitian dari Hariyanti, Askandar, \& Mawardi (2019), dengan temuan bahwa terdapat pengaruh yang positif dan signifikan antara inflasi dengan Rahn, sedangkan hasil dari penelitian Rosa, Husni, \& Idwar (2017), dengan temuan bahwa inflasi tidak berpengaruh terhadap penyaluran Rahn. Penelitian dari Pratiwi (2014), diperoleh hasil bahwa kurs berpengaruh negatif dan signifikan terhadap penyaluran dana, tetapi hasil dari penelitian Lisa, \& Setiawan (2019), dengan temuan bahwa kurs tidak signifikan terhadap penyaluran Rahn. Hasil penelitian dari Mamulati (2020), terungkap bahwa harga emas berpengaruh positif dan signifikan terhadap penyaluran Rahn. 
Rahn pada saat ini sudah menjadi salah satu alternatif sumber pembiayaan yang diandalkan masyarakat, terutama yang ingin menerapkan prinsip syariah secara utuh, agar memperoleh keberkahan (Budiono, 2017). Hal ini, merupakan peluang besar bagi perbankan syariah untuk mengembangkan produk Rhan. Namun, dalam penyaluran Rahn dapat dipengaruhi faktor internal dan eksternalnya, karena akan mempengaruhi kemampuan masyarakat dalam mengembangkan usaha dan kemampuan memenuhi kewajibannya, sehingga berdampak pada permintaan masyarakat terhadap Rahn. Untuk itu, perlu dilakukan penelitian faktor-faktor yang mempengaruhi penyaluran Rahn.

\section{METODE PENELITIAN}

Penelitian ini untuk mengatahui faktor-faktor yang mempengaruhi penyaluran Rahn. Penyaluran Rahn merupakan variabel terikat dan variabel bebasnya menggunakan inflasi, kurs, dan harga emas. Metodenya menggunakan regresi, dengan data berupa kuartalan pada 2011-2018, yang bersumber dari Badan Pusat Statistik, Bank Indonesia, Bank Syariah Mandiri dan PT. Aneka Tambang. Untuk mengetahui hasil dari penelitiannya dilakukan analisis terhadap uji $\mathrm{F}$, uji $\mathrm{t}$, dan Adj-Rsquare. Adapun model yang digunakan adalah:

$$
\operatorname{Rahn}_{t}=\beta_{0}+\beta_{1} I N F_{t}+\beta_{2} E_{t}+\beta_{3} G \operatorname{cold}_{t}+\varepsilon_{t}
$$

Keterangan:

Rahn = Penyaluran Rahn (juta rupiah).

INF = Inflasi (persen).

ER $=$ Kurs (rupiah per 1 dolar Amerika).

Gold = Harga Emas (rupiah).

$\beta_{0} \quad=$ Konstanta.

$\beta_{1}, \beta_{2}, \beta_{3}=$ Koefisien.

\section{Pengaruh inflasi terhadap penyaluran Rahn.}

Inflasi yang wajar menandakan bahwa perekonomian sedang mengalami pertumbuhan dengan tren yang positif, sehingga prospek dari aktivitas ekonominya semakin baik. Hal ini, membuat semakin banyak pengusaha meningkatkan investasinya, dengan ekspektasi bisnis yang dijalankan akan memberikan keuntungan yang lebih besar, sehingga mereka meningkatkan permintaan Rahn. Pihak lembaga pembiayaan dengan kondisi ekonomi ini, melakukan ekspansi usahanya, sehingga lembaga pembiayaan semakin agresif dalam meningkatkan penyaluran Rahn. Untuk itu, dapat dibuat $\mathrm{H}_{1}$ : Inflasi berpengaruh positif dan signifikan terhadap penyaluran Rahn.

\section{Pengaruh kurs terhadap penyaluran Rahn}

Kurs rupiah yang terdepresiasi menyebabkan nilainya turun. Artinya, dalam memperoleh dolar yang sama diperlukan rupiah yang lebih banyak, sehingga meningkatkan kewajibannya. Untuk itu, pihak investor yang banyak menggunakan konten impor dalam berproduksi, akan mengurangi investasinya akibat biaya yang dikeluarkannya semakin besar, sehingga kebijakan yang diambil investor akan berdampak pada penurunan permintaann Rahn. Hal ini, juga membuat pihak lembaga pembiayaan merasakan peningkatan risiko bisnis, akibat perekonomian yang tidak menentu, sehingga untuk mengatasinya akan mengurangi penawaran Rahn. Untuk itu, dapat dibuat $\mathrm{H}_{2}$ : Kurs berpengaruh negatif dan signifikan terhadap penyaluran Rahn.

\section{Pengaruh harga emas terhadap penyaluran Rahn}

Harga emas yang stabil dengan kecenderungan meningkat membuat pemiliknya memiliki kemampuan untuk membayar kewajibannya, sehingga meningkatkan permintaan terhadap Rahn. Pihak lembaga pembiayaan juga menyukai komoditi ini, karenakan nilainya yang semakin tinggi, sehingga akan meningkatkan penawaran Rahn. Hal ini, berdampak pada semakin tingginya harga emas akan meningkatkan permintaan Rahn. Untuk itu, dapat dibuat $\mathrm{H}_{3}$ : Harga emas berpengaruh positif dan signifikan terhadap penyaluran Rahn.

\section{HASIL DAN PEMBAHASAN}

\subsection{Hasil penelitian}

Perkembangan penyaluran Rahn, inflasi, kurs, dan harga emas pada 2011.1-2018.4 memiliki tren yang beragam. Penyaluran Rahn rata-ratanya sebesar 3.887.935 juta rupiah dengan standar deviasi sebesar 1.684.036 juta rupiah. Penyaluran Rahn tertinggi pada 2011.4 sebesar 6.529 .139 juta rupiah dan terendahnya pada 2016.1 sebesar 1.678.926 juta rupiah. Inflasi memiliki rata-rata sebesar 4,96 persen dengan standar deviasi sebesar 1,75 persen. Inflasi tertinggi terjadi pada 2013.3 sebesar 8,4 persen dan terendah pada 2018.3 sebesar 2,88 persen. Kurs rupiah terhadap dolar Amerika memiliki rata-rata sebesar 11.941 rupiah per 1 dolar Amerika dengan standar deviasi sebesar 1.910 rupiah per 1 dolar Amerika. Nilai kurs rupiah tertinggi sebesar 8.658 rupiah per 1 dolar 


\section{Jurnal Ilmiah Ekonomi Islam, 7(02), 2021, 690}

Amerika pada 2011.3 dan terendah sebesar 14.684 rupiah per 1 dolar Amerika pada 2018.3. Harga emas memiliki tren yang meningkat, dengan rata-ratanya sebesar 572.012 rupiah dan standar deviasi sebesar 38.391 rupiah. Emas memiliki harga tertinggi pada 2018.4 sebesar 645.000 rupiah dan terendah sebesar 467.000 rupiah pada 2011.1 .

Hasil dari penelitian ini diperoleh nilai F-Statistik sebesar 33,4027 dengan signifikansi 0,0000, sehingga nilai signifikansi $0,0000<0,05$, yang artinya minimal terdapat satu dari inflasi, kurs, dan harga emas yang dapat mempengaruhi penyaluran Rahn. Nilai dari AdjRsquare diperoleh sebesar 0,7582 , yang artinya variasi dari inflasi, kurs, dan harga emas dapat menjelaskan terhadap penyaluran Rahn sebesar 75,82 persen, sedangkan sisanya yang 24,18 persen dapat dipengaruhi variabel lain tetapi tidak dimasukkan ke dalam model.

Tabel 1. Hasil Pengolahan Data Penelitian

\begin{tabular}{cccccc}
\hline Variable & Cefficient & Std. Error & t-Statistic & Prob. \\
\hline C & -1041941 & 2903046 & -0.358913 & 0.7224 \\
INF & 290297.5 & 98765.65 & 2.939255 & 0.0065 \\
ER & -910.8085 & 99.43592 & -9.159754 & 0.0000 \\
Gold & 25.11362 & 5.416261 & 4.636708 & 0.0001 \\
\hline
\end{tabular}

Sumber: Data hasil olahan penelitian, 2020

Inflasi memiliki koefisien sebesar 290297,5 dengan signifikansi sebesar 0,0065 , sehingga nilai signifikansi $0,0065<0,05$, yang artinya bahwa inflasi memiliki pengaruh positif dan signifikan terhadap penyaluran Rahn. Kurs memiliki koefisien sebesar minus 910,8085 dengan signifikansi sebesar 0,0000, sehingga nilai signifikasi $0,0000<0,05$, yang artinya bahwa kurs memiliki pengaruh negatif dan signifikan terhadap penyaluran Rahn. Harga emas memiliki koefisien sebesar 25,11362 dengan signifikansi sebesar 0,0001, sehingga nilai signifikansi $0,000<0,5$, yang artinya harga emas memiliki pengaruh positif dan signifikan terhadap penyaluran Rahn.

\subsection{Pembahasan}

Inflasi memiliki pengaruh positif dan signifikan terhadap penyaluran Rahn. Artinya, meningkatnya inflasi akan diikuti dengan peningkatan penyaluran Rahn dan begitu pula sebaliknya, menurunnya inflasi akan diikuti penurunan penyaluran Rahn. Hasil ini, sesuai dengan penelitian yang dilakukan Hariyanti, Askandar, \& Mawardi (2019). Hal ini, dapat terjadi karena adanya pertumbuhan ekonomi akan diikuti dengan peningkatan inflasi, sehingga pada saat inflasi yang wajar dapat mempercepat perkembangan usaha. Untuk itu, masyarakat perlu melakukan peningkatan investasi dengan meningkatkan pinjaman Rahn.

Kurs memiliki pengaruh negatif dan signifikan terhadap penyaluran Rahn. Artinya, menurunnya kurs akan diikuti dengan peningkatan penyaluran Rahn dan begitu pula sebaliknya, meningkatnya kurs akan diikuti menurunkan penyaluran Rahn. Keadaan ini, sesuai hasil dari penelitian Pratiwi (2014). Pada era globalisasi, membuat dunia menjadi tanpa batas, sehingga adanya perubahan makro ekonomi dunia, akan mempengaruhi perekonomian dalam negeri suatu negara. Dengan demikian, adanya perubahan kurs yang ekstrim, membuat banyak negara mengalami krisis. Dalam kondisi ini, risiko yang dihadapi semakin besar, sehingga pelaku usaha mengurangi investasinya dan akhirnya akan menurunkan permintaan Rahn.

Harga emas memiliki pengaruh positif dan signifikan terhadap penyaluran Rahn. Artinya, meningkatnya harga emas akan diikuti dengan peningkatan penyaluran Rahn dan begitu pula sebaliknya, menurunnya harga emas akan diikuti penurunan penyaluran Rahn. Hasil ini, sesuai dengan penelitian yang dilakukan Mamulati (2020). Meningkatnya investasi akan diikuti dengan semakin besarnya keuntungan yang diperoleh, sehingga adanya peningkatan harga emas, membuat masyarakat semakin tertarik untuk menggadaikan emasnya, karena dana yang dapat diperoleh semakin banyak.

Emas merupakan komoditas yang memiliki nilai intrinsik dan ekstrinsik relatif stabil, sehingga dapat diandalkan masyarakat untuk menjaga nilai riil dari uangnya. Untuk itu, masyarakat yang memiliki dana lebih akan tertarik melakukan investasi pada komoditas ini. Inflasi tetap diperlukan untuk menggerakan roda perekonomian, namun pemerintah perlu menjaga agar inflasi pada taraf yang wajar, agar minat investasi masyarakat tetap kondusif. Kurs memiliki peran yang besar dalam mempengaruhi makro ekonomi suatu negara, untuk itu pemerintah perlu menjaga kestabilan nilai kurs, agar tidak memberatkan kewajiban bagi investor dalam menjalankan usahanya. Penyaluran Rahn yang dilakukan Bank Syariah mandiri selain memperhatikan faktor harga emas, inflasi dan kurs, perlu mengikuti perkembangan zaman dengan mengembangkan pinjaman yang menggunakan financial technology, tetapi tetap menerapkan prinsip syariah. 


\section{KESIMPULAN}

Penelitian pengaruh inflasi, kurs, dan harga emas terhadap penyaluran Rahn di Bank Syariah Mandiri menggunakan metode regresi. Variabel terikat menggunakan penyaluran Rahn dan variabel bebasnya menggunakan inflasi, kurs, dan harga emas. Adapun hasilnya variasi dari inflasi, kurs, dan harga emas dapat menjelaskan terhadap penyaluran Rahn sebesar 75,82 persen. Inflasi berpengaruh positif dan signifikan terhadap penyaluran Rahn, kurs berpengaruh negatif dan signifikan terhadap Rahn, serta harga emas berpengaruh positif dan signifikan terhadap penyaluran Rahn. Pegadaian emas masih layak untuk dikembangkan karena memiliki nilai intrinsik dan ekstrinsik relatif stabil, sehingga dapat diandalkan masyarakat untuk menjaga nilai riil dari uangnya. Pemerintah perlu menjaga kestabilan inflasi dan kurs, agar perekonomian nasional dapat tumbuh dengan baik. Pihak Bank Syariah mandiri selain memperhatikan faktor internal dan eksternal, perlu mengikuti perkembangan zaman dengan mengembangkan pegadaian emas dengan memanfaatkan financial technology. Untuk penelitian selanjutnya, sebaiknya memasukan indeks kepuasan pelayananan lembaga keuangan dan pendapatan masyarakat.

\section{REFERENSI}

Astuti, W. R. D. (2020). Kerja sama G20 dalam Pemulihan Ekonomi Global dari COVID 19. Andalas Journal of International Studies, 9(2), 131-148. https://doi.org/10.25077/ajis.9.2.131148.2020

Budiono, A. (2017). Penerapan Prinsip Syariah Pada Lembaga Keuangan Syariah. Jurnal Law and Justice, 2(1). 54-65. https://doi.org/10.23917/laj.v2i1.4337

Dja'akum, C. R. (2017). Restruktrurisasi Sebagai Alternatif Penyelesaian Pembiayaan Bermasalah Dalam Perbankan Syari'ah. Az Zarqa', 9(1), 4765.

Diana. (2017). Prosedur Pembiayaan Gadai Emas di PT Bank Syariah Mandiri Cabang Pasuruan. MALIA, 9(1), 135-150. https://doi.org/10.35891/ml.v9i1.917

Fauziah, M.R. (2019). Investasi Logam Mulia (Emas) di Penggadaian Syariah Dalam Perspektif Hukum Ekonomi Syariah. Tahkim, 15(1), 63-73. http://dx.doi.org/10.33477/thk.v15i1.866
Fauziah, A., \& Surya, M. E. (2016). Peluang Investasi Emas Jangka Panjang Melalui Produk Pembiayaan BSM Cicil Emas (Studi Pada Bank Syariah Mandiri K.C. Purwokerto). Islamadina, 16(1), 57-73. https://doi.org/10.30595/islamadina.v0i0.1817

Fadilah, N., \& Soeharjoto. (2016). Determinasi Permintaan Pembiayaan Konsumsi Bank Umum Syariah di Indonesia. Media Ekonomi, 24(1), 2736. http://dx.doi.org/10.25105/me.v24i1.3786

Fatwa DSN-MUI Nomor 26/DSNMUI/2002 tentang Rahn Emas.

Fatwa DSN-MUI Nomor.25/DSNMUI/III/2002 tentang Rahn.

Hariyanti, B. I., Askandar, N. S., \& Mawardi, M. C. (2019). Pengaruh Pendapatan, Harga Emas, Tingkat Inflasi Terhadap Penyaluran Pembiayaan Rahn (Studi Kasus Pada Pegadaian Syariah Bonder Lombok Tengah). Jurnal Ilmiah Riset Akuntansi. 8(1). 1-15.

Lisa, M. J.N., \& Setiawan, M. A. (2019). Pengaruh Kurs, Inflasi, Dana Pihak Ketiga (DPK), Pendapatan Bank, Capital Adequacy Ratio (CAR), dan Non Performing Financing (NPF) Terhadap Tingkat Pengguliran Dana Bank Umum Syariah Non Devisa Periode 2014-2018. Jurnal Eksplorasi Akuntansi, 1(3). 1472-1493. https://doi.org/10.24036/jea.v1i3.156

Malarangan, H., Irfan, I., Haekal, A., \& Istiqamah, R. (2020). Analisis Tanggung Jawab Pegadaian Syariah Palu Plaza Terhadap Barang Jaminan yang Hilang dan Rusak. Jurnal Ilmu Ekonomi dan Bisnis Islam, 2(1), 15-35. https://doi.org/10.24239/jiebi.v2i1.21.15-35

Mamulati, I. (2020). Pengaruh Pendapatan Pegadaian, dan Harga Emas Terhadap Penyaluran Pembiayaan Rahn. KAWASA, 10(1).1-8.

Pratiwi, R. D. (2014). Faktor-Faktor Yang Mempengaruhi Tingkat Pengguliran Dana Bank Umum Non Devisa Syariah Tahun 2010-2012. Media Ekonomi dan Teknologi Informasi, 22(1), 15-31.

Peraturan Bank Indonesia Nomor: 10/17/PBI/2008 tentang Produk Bank Syariah dan Unit Usaha Syariah

Rosa, Y. D., Husni, E., \& Idwar. (2017). Pengaruh Tingkat Inflasi dan Pendapatan Pegadaian Terhadap Penyaluran Kredit Rahn Pada Pegadaian Syariah di Indonesia Tahun 20072015. Menara Ekonomi. 3(5). 116-127. https://doi.org/10.31869/me.v3i5.211 
Jurnal Ilmiah Ekonomi Islam, 7(02), 2021, 692

Soekapdjo, S., \& Danova, G. K. (2020). Pengaruh Makro Ekonomi Terhadap Cadangan Devisa Di Asean-5. Jurnal Ecodemica, 4(1), 68-76. https://doi.org/10.31294/jeco.v4i1.7732

Soekapdjo, S., Nugroho, L., Badawi, A., \& Utami, W. (2018). Bad Debt Issues in Islamic Bank: Macro and Micro Influencing (Indonesia Cases). International Journal of Commerce and Finance, $4(1), 10-26$.

Surepno, (2018). Studi Implementasi Akad Rahn (Gadai Syariah) Pada Lembaga Keuangan Syariah. Tawazun, 1(2), 174186. http://dx.doi.org/10.21043/tawazun.v1i2.5 090

Setiawan, I. (2015). Pelaksanaan Gadai Pada Perbankan Syariah di Indonesia. Adliya, 9(1), 115-166.

https://doi.org/10.15575/adliya.v9i1.6161
Surat Edaran Bank Indonesia (SE-BI) Nomor 14/7/DPbS tentang Produk Qardh beragunan Emas bagi Bank Syariah dan Unit Usaha Syariah Surat Edaran Bank Indonesia Nomor. 10/31/DPbS/2008 tentang Produk Bank Syariah dan Unit Usaha Syariah

Tribudhi, D. A., \& Soekapdjo, S. (2019). Determinasi transaksi dengan menggunakan uang elektronik di Indonesia. KINERJA, 16 (1), 7884. http://dx.doi.org/10.29264/jkin.v16i1.5218

Turmudi, M. ( 2016). Operasional Gadai Dalam Sistem Hukum Ekonomi Islam. Jurnal Al-'Adl, 9(1), 162-173. https://doi.org/10.31332/aladl.v9i1.673 